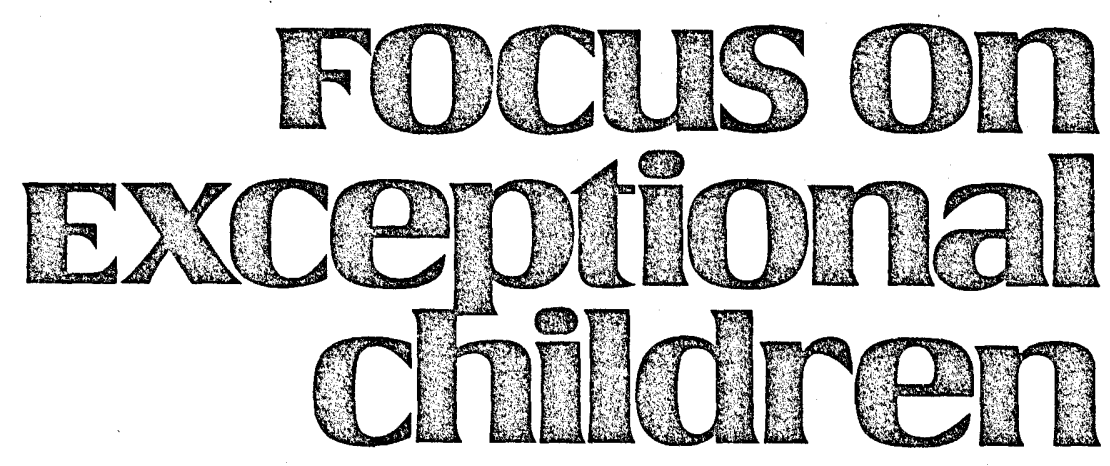

\title{
Employment for Persons with Severe Handicaps: Curriculum Development and Coordination of Services
}

\author{
Frank R. Rusch and Janis Chadsey-Rusch
}

One of the primary outcomes of education is preparation for adulthood. With adulthood come certain responsibilities and roles that we are all expected to assume. One of these roles is that of "contributor to society,"which can be achieved in various ways, including finding and maintaining employment. Employment is also important to the individual. Through employment one derives monetary rewards, which can be used to purchase desired goods and services; employment also provides intangible rewards such as the opportunity to interact with others, the development of self-worth, and the chance to contribute to society (Turkel, 1972). Employment is tantamount to our daily lives because it structures our individual adjustment and influences our residential and recreational opportunities.

Assistant Secretary of the Office of Special Education and Rehabilitative Services, Madeleine Will (1984) also has suggested that employment is critical to the lives of most Americans regardless of whether their work is specialized (e.g., banking, computer science, medicine), entry-level (e.g., maid services, janitorial services, food services), or supported (e.g., work crews, enclaves). Will's statement has important implications for persons with severe handicaps because these individuals are likely to be employed in entry-level or supported employment positions. Unfortunately, prevailing educational and adult services in this country have resulted in few employment opportunities to persons with severe handicaps.

Recently the U.S. Commission on Civil Rights (1983) reported that the percentage of all persons with disabilities who are unemployed is between $50 \%$ and $80 \%$. These data suggest that a disproportionately large number of disabled persons, and practically all those labeled severely handicapped by the schools, do not obtain meaningful jobs. Several recent follow-up studies conducted in Vermont (Hasazi, Preskill, Gordon, \& Collins, 1982), Virginia (Wehman, Kregel, \& Zoller, 1984), and Colorado (Mithaug, Horiuchi, \& Fanning, 1985) reflect similar employment figures. For example, Wehman et al. (1984) indicated that less than $12 \%$ of all severely handicapped individuals are employed in Virginia and all of these persons are underemployed.

Frank Rusch is Associate Professor of Special Education, Office of Career Development for Special Populations, the University of Illinois at Urbana-Champaign, where Janis Chadsey-Rusch is Assistant Professor, Department and Vocational and Technical Education.

๑ Love Publishing Company, 1985 
Although considerable attention has been focused upon elementary and secondary education over the past few years, these resources have not resulted in meaningful employment outcomes for graduating students who are severely handicapped. Consequently, we are at a crucial point in our education of persons with severe handicaps. It is time to implement the current "best practices" in order to prepare students who are severely handicapped for adulthood, particularly if adulthood includes employment. Undoubtedly, more research and development must occur to further refine and clarify the "best practices" in employment preparation. In fact, with the exception of a single text (i.e., Wilcox \& Bellamy, 1983) and a few chapters and articles, educational "best practices" related to employment for students who are severely handicapped appear to have not attained a level of universal adoption that results in meaningful outcomes-i.e., employment.

All students with severe handicaps should be prepared for employment. Further, this preparation should take place when the student is between the ages of 13 and 21 . Not only should preparation for employment begin in the schools, but school personnel also must assume a leadership role in enhancing students' meaningful transition

\section{Focus on
Exceptional
childiren}

FOCUS ON EXCEPTIONAL CHILDREN (ISSN0015-511X) (USPS 203-360) is published monthly except June, July, and August as a service to teachers, special educators, curriculum specialists, administrators, and those concerned with the special education of exceptional children. This journal is abstracted and indexed in Exceptional Child Education Resources, and is also available in microform from Xerox University Microfilm. Ann Arbor, Michigan. Subscription rates, $\$ 18.00$ per year. Copyright $\odot$ 1985. Love Publishing Company. All rights reserved. Reproduction in whole or part without written permission is prohibited. Printed in the United States of America. Second class postage is paid at Denver, Colorado.

POSTMASTER: Send address changes to:

Love Publishing Company

Executive and Editorial Office

1777 South Bellaire Street

Denver, Colorado 80222

Telephone (303) 757-2579

EDITORIAL BOARD

Edward L. Meyen

University of Kansas

Richard J. Whelan

University of Kansas Medical Center
Glenn A. Vergason

Georgia State University
Stanley F. Love

Publisher
Carolyn Acheson

Senior Editor from school to work. This article provides curriculum guidelines that will enable school personnel to assume this role. It also describes the need for coordinated services that will result in an effective, efficient transition from school to work.

\section{GUIDELINES FOR CURRICULUM DEVELOPMENT}

The following guidelines focus upon four interrelated steps suggested by Rusch (1983), Wehman (1981), and others that have been shown to result in meaningful employment outcomes. ${ }^{1}$ These steps form a model whereby the community is first surveyed to identify possible job placement and their associated social and vocational survival skills (Rusch, 1979). Next, community-based (nonsheltered) training sites are established within actual community work settings, and the student is trained in the work setting (the nonsheltered training site). Third, a job is found for the student and the student is placed. Finally, training and supervision are provided to the student on the job during initial placement and later at regular intervals to ensure that acquired skills are maintained and the student successfully adjusts to employment.

This curriculum model is important because it provides the blueprint for teachers to consider when establishing a program's philosophical commitment. The commitment includes establishing a curriculum that is (a) community-referenced, (b) integrated, (c) longitudinal, and (d) community-based.

\section{Community-Referenced Approach}

Community-referenced curricula answer the "what to teach" question by identifying the behaviors students must be able to perform in employment settings in which they are going to be placed. The community-referenced approach does not follow more traditional approaches to curriculum development that are organized along academic sequences (e.g., language, reading, math). Instead, this approach focuses upon the basic demands of adult life (e.g., employment, leisure, community participation). This guideline has opened a new arena for curriculum plamning that may prove to be as influential to students with handicaps as was the identification of goals and objectives in the 1960s and the formation of individualized education plans in the 1970s.

\footnotetext{
${ }^{1}$ Meaningful employment refers to working in integrated settings whereby all employees work for mutual outcomes - production of useful services or valued goods for monetary reward.
} 
Briefly, in developing a community-referenced curriculum, the local community is surveyed to determine (a) the types of jobs available and (b) the requirements of the jobs identified. Bates (in press) has described six methods for determining available community jobs: (a) listing previously successful employment options of past graduates, (b) keeping a record of the frequency with which specific types of jobs appear in classified ads, (c) obtaining a list of employment openings from local rehabilitation counselors, (d) conducting surveys of local, businesses, (e) utilizing personal contacts with community leaders (e.g., principals, small business operators), and (f) visiting other successful programs. Jobs that have been identified as potential employment options for students in the Champaign-Urbana (Illinois) area are:

\author{
Assembly Line Worker \\ Baggage Transporter \\ Bakery Assistant (doughnut filler/finisher) \\ Candy-Striper \\ Concession Stand Worker \\ Copy Shop Assistant \\ Dishwasher \\ Doctor or Dentist Office (cleaning instruments) \\ Gardener/Greenskeeper (planting and tagging shrubs, \\ small trees) \\ Grocery Store/Supermarket Bagger, Carryout \\ Linen Room Assistant \\ Meter Maid (emptying meters) \\ Painter's Assistant \\ Pet Care Assistant (Humane Society) \\ Plugger (cabinet company) \\ Postal Worker (mail sorter) \\ Surgical Instrument Wrapper \\ Vending Room Supplier/Attendant
}

Once a listing of potential jobs has been generated, the specific "survival skills" required in each of the potential job sites is identified. Survival skills are generally thought of as those behaviors that facilitate functioning in the community (Martin, Rusch, \& Heal, 1982). In relation to employment, survival skills are those that, when acquired, increase the likelihood of employment and job maintenance (Rusch, 1979). Survival skills usually are divided into two categories-social survival skills and vocational survival skills. Social survival skills are those that require interaction with other persons-e.g., exchanging greetings and following directions. Vocational survival skills refer to the nonsocial skills required on the job-e.g., completing $\mathrm{d}$ task assignment and moving from one task to another throughout the work day.
Identifying social and vocational survival skills is important because this information results in a better understanding of what students should learn in school. Teachers then can use the identified survival skills (the actual requirements of the job) as a basis for selecting instructional objectives. These objectives, when taught, will likely result in meaningful employment outcomes for students with severe handicaps when they leave school.

Survival skills can be identified by (a) verbal reports or (b) direct observation. Verbal reports usually involve an interview with an employer, a job supervisor, or even an employee, who describes the requirements for a specific job (Rusch \& Mithaug, 1980). Often, employers have difficulty identifying survival skills because few employers have ever really described the specific behaviors necessary to get and maintain a job. For example, rather than saying that an employee should be able to ask for help when needed, an employer may state that an employee needs to be a "good worker." These broad, general statements are not helpful for formulating instructional objectives. Thus, teachers must structure the interview so that employers specify the important requirements for the job, as well as the possible standards and criteria that go along with the job requirements.

Often, using a questionnaire to solicit specific survival skills information may be helpful. For example, one of the items on a questionnaire administered by Rusch, Schutz, and Agran (1982) asked employers to indicate how long they expected employees to work continuously (0-15 minutes, 15-30 minutes, 30-60 minutes, 1-2 hours, or more than 2 hours).

Another method that can be used for determining social and vocational survival skills is through direct observation of workers performing targeted jobs (Rusch \& Mithaug, 1980). Teachers, however, must have some direction about the behaviors they are going to observe before they begin to collect information, or else they may spend time observing behaviors that are not necessarily essential to job functioning. Guidance on the valued job skills to observe can again come from the employer, supervisor, or other employees. Direct observation of workers performing jobs has one advantage over getting this information strictly through verbal reports or questionnaires: It allows the teacher to see first-hand what types of job skills are critical for success rather than relying on verbal reports, which may over- or underestimate, or even misrepresent the actual requirements for the job.

After teachers have compiled a list of potential jobs and identified the critical vocational and social survival skills needed for job success, they must still decide which type of job is most appropriate for individual students. This decision can be facilitated by assessing parent and 
student preference for the specific jobs available in the community and by determining how well the student's skills match the social and vocational skills needed for the job.

Again, a community-referenced curricula consists of specific behaviors, or survival skills, that students must be able to perform in employment settings in which they are going to be placed. Local communities are surveyed for the types of jobs available and the requirements for the jobs (i.e., social and vocational survival skills) are identified by verbal report and/or direct observation.

\section{Integrated Settings}

The traditional occupational choice for students who are severely handicapped has been the sheltered workshop or similar segregated settings, such as adult day care centers and work activities centers. Usually, these segregated settings offer limited work opportunities. Consequently, little training for specific jobs occurs. If work is available, it most often represents work performed in nonsheltered settings in the community by persons who are not handicapped. This work then is subcontracted to segregated settings for persons who are handicapped. Typically, sheltered workshop employees work at subminimum wages, completing tasks such as assembling, packaging, or sorting "widgets," for periods of less than 2 to 3 hours per day. From a rehabilitative perspective this work is viewed as therapeutic. From our perspective this work is viewed as demeaning and does not contribute to the individual's growth and development.

Students with severe handicaps should be prepared to work in settings with nonhandicapped persons. Employment preparation in integrated settings allows the student to have exposure to and experience with the demands and expectations of these environments. Integrated settings also provide employers and co-workers opportunities to interact with students who have handicaps. Through this symbiotic relationship the student can more easily learn appropriate social and vocational skills needed for the job, and the employer and co-workers can learn of the student's potential as a reliable employee and friend. Often, as a consequence of integrated teaching environments, students may also earn a more competitive wage.

\section{Longitudinal Instruction}

As students with severe handicaps move from one instructional level to the next (e.g., from intermediate to secondary classrooms), they should acquire a range of skills that will eventually lead to employment. For example, if working continuously at a job for 1- to 2-hour intervals has been identified as a survival skill needed to enter a community work situation, curricula should be developed so that this skill is in the students' repertoire by the time they leave high school.

One way to ensure that this objective is reached is to begin work on the skills early in the educational sequence of classes. Thus, preschool through high school experiences should include instruction that develops identified survival skills. Regarding the goal "work continuously at the job for 1- to 2-hour intervals," preschool students might be required to participate in direct instruction for at least 15 minutes per day. This would be extended to increasingly longer periods as the students grow and progress through the educational sequence of classes. Eventually they would work continuously for at least 30- to 60-minute periods in community job stations.

Each teacher's major responsibility is to teach skills required in future placements. Acquiring a list of the social and vocational skills potential employers believe are critical for job entry allows the teacher to develop a coordinated, longitudinal curriculum. Preschool, elementary, and intermediate classroom teachers should develop instructional programs that advance students from general applications of each skill to employer-specific task applications, which is the responsibility of the secondary classroom teacher.

Instructional content should be based on goals that are sequenced and on what is functional for each student. Functionality within the context of employment preparation refers to teaching relevant, age-appropriate applications of survival skills identified as important for eventual job entry. For example, a student might learn to move independently around the classroom, from the classroom to the cafeteria for lunch, then to the playground, and eventually from home to work. At the secondary level all skills should be taught on placement-specific tasks, such as riding the bus to and from a community-based employment training station.

\section{Community-Based Training Stations}

One of the significant learning problems students with severe handicaps possess is that they often do not generalize, or transfer, skills they have acquired across settings, people, behaviors, and/or time. Educational efforts to date reflect the assumption that what is learned in the classroom or during simulated work stations will also be performed outside of the school or in real work situations. Since this assumption is frequently faulty, teachers must establish and provide instruction in community-based training stations. 
Establishing community-based training stations in actual employment settings is one way of providing realistic and functional training for employment. A community-based training station is a vocational training site within an ordinary community work setting (e.g., in dishwashing rooms in restaurants, in industrial plants) (Stainback, Stainback, Nietupski, \& Hamre-Nietupski, in press). One of the major implications of communitybased instruction is that students will receive less and less instruction in the classroom. In fact, when a student reaches the age of 12 , instruction in the community should occur for extended periods. This means that school personnel will have to provide instruction on job sites in the community outside of the classroom. Communitybased job sites also must be community-referenced; they must be established where there is a potential market for employment. Since students will likely hold more than one job in their lifetime, they must learn skills that are useful across jobs.

Community-based training sites have been successfully established and maintained by special education teachers (Alper, 1981; Nietupski, Hamre-Nietupski, Welch, \& Anderson, 1983). Compared to sheltered, segregated, and simulated work settings, community-based training stations offer many advantages, some of which are listed below.

1. Training of vocational survival skills is ensured.

2. Opportunities to learn social survival skills is provided.

3. Co-workers serve as role models.

4. Co-workers begin to understand persons who are severely handicapped.

5. Direct service personnel become familiar with employment.

6. A more normalized learning experience is offered.

7. Community members' expectations are influenced positively.

8. The likelihood of employment is enhanced.

As much as possible, special educational personnel should capitalize on these advantages by trying to establish community work stations as primary settings for vocational training of students who are severely handicapped.

\section{Summary of Curriculum Guidelines}

Guidelines that have resulted in meaningful employment outcomes for students who are severely handicapped include the development of a community- referenced, integrated, longitudinal, and communitybased curriculum. A community-referenced curriculum focuses upon the "actual" demands of the local communities and jobs and pinpoints objectives that guide the development of students' IEPs. The integrated guideline is important because it directs attention toward equitable opportunities for training and placement. Longitudinal and community-based guidelines refer to skills being taught in the community that are functional and that share some commonality throughout the student's school years.

When students with severe handicaps graduate from school, many will still need specialized services after job placement, including continued job training, through follow-up. Unfortunately, when the student is severely handicapped, few agencies provide post-school services along the guidelines just discussed. Coordination of services between school and rehabilitation personnel is needed to enhance the transition from school to work.

\section{COORDINATION OF SERVICES}

Consider the case of Bob. Bob is a student with severe mental retardation who was educated in a local public school system and had received vocational training ever since he was in junior high school. Bob was taught to ride the bus with assistance, learned to express himself with the use of a communication book (e.g., he pointed to pictures when he was hungry, had to go to the bathroom, was sick, or needed help), could use the restroom independently, and was able to bus tables (he could pick up dirty dishes from a table and then wipe the table clean). When Bob left the public school system, he was referred to the local rehabilitation agency and was placed in an adult day care center.

When Bob's teachers learned of his placement, they were furious! Why, they asked, had they bothered to educate Bob using a curriculum that was communityreferenced, integrated, longitudinal, and communitybased if Bob was going to be placed into an adult day care care center? Similarly, the local rehabilitation staff was angry. Why, they asked, had not the school system contacted them before Bob graduated so they could have worked together to make certain Bob was continued in the job for which he was trained? Had they known about Bob and his skills, they could have worked actively with the schools, Bob, and his parents to ensure that the transition from school to work was efficient, appropriate, and mutually agreed upon.

Unfortunately, the above scenario happens all too frequently in communities in the United States. Even 
more unfortunately, individuals like Bob and his family are the ones who suffer the most from lack of communication and coordination between and among service providers. Educational and rehabilitation programs cannot effectively serve students who are severely handicapped until both service providers make an effort to plan and coordinate their services. Coordinated services (a) provide a more efficient, effective, and meaningful continuum of services for students, (b) help reduce duplicative efforts, and (c) offer service personnel additional knowledge and appreciation for each other's roles in service delivery (Hall, 1980).

Transition is a term that has been used for several years (Brown et al., 1981). Recently, Wehman (1984) defined vocational transition as:

\begin{abstract}
.. . a carefully planned process, which may be initiated either by school personnel or adult service providers, to establish and implement a plan for either employment or additional vocational training of a handicapped student who will graduate or leave school in three to five years. Such a process must involve special educators, vocational educators, parents and/or the student, and an adult service system representative, and possibly an employer. (pp. 23-24)
\end{abstract}

According to Wehman's definition, vocational transition must be: (a) a well-planned and systematic process, which (b) occurs well before the student reaches 21 years of age, and combines the efforts of (c) individuals from numerous disciplines and service agencies, and (d) parents or students, or both. This coordination is achieved by developing and implementing a vocational transition plan. Like the IEP, a vocational transition plan helps to ensure that educational and rehabilitation personnel meet and pool their resources so that students will obtain employment or additional vocational training after leaving high school.

\section{The Transition Planning Team}

Several individuals can be involved in planning for transition, including parents, students, school personnel, rehabilitation personnel, and employers.

\section{Parents}

Parents are crucial to the transition team because they usually make the ultimate decision regarding which employment options are the most desirable for their children. Parental choices vary depending upon their personal values, expectations for their children, and information they possess about program options (McDonnell, Sheehan, \& Wilcox, undated). So that the best decisions can be made for students, parents have to be well informed regarding the employment options existing in their communities. Employment options that are common to many communities include work activity centers, sheltered workshops, supported employment, and competitive employment.

Work Activity Centers. Work activity centers are day programs in which 20 to 60 individuals with handicaps spend their day performing activities that bear little if any relation to employment (e.g., coloring, dressing a doll, sitting quietly). Few work activity centers offer employment training or wages; most centers focus their training efforts on leisure activities such as arts and crafts. If wages are offered, they generally are quite low (e.g., less than $\$ 300$ a year).

Sheltered Workshops. Although the goal of sheltered workshops is to prepare individuals for competitive employment, actual placement out of the workshop seldom occurs. If work is offered and wages are paid, the wages are often low (about $\$ 700$ a year). Sheltered workshops, like work activity centers, are segregated and employ large number of individuals with handicaps (50100). Few persons who are severely handicapped attain sheltered workshop status; most workshops employ individuals who are mildly or moderately handicapped.

Supported Employment. Supported employment options include work crews and enclaves, which exist in only a few communities. Work crews generally consist of small groups of individuals who are handicapped and under the supervision of an individual who is not handicapped. Work crews perform jobs according to specified contracts that are bid upon (e.g., yard work or janitorial services at an office building). Work crews usually move from one job to another job throughout a work day. Enclaves are located within a single business or industry performing light industrial or electronic assembly tasks. Similar to work crews, enclaves consist of a group of individuals with handicaps who are trained and supervised by a nonhandicapped individual. Both employment options assume that the individual worker will require continuing support throughout the tenure of employment. Thus, this option is a viable one for individuals who are severely handicapped. Supported employment options most often occur in integrated settings and offer competitive wages for full- or part-time work.

Competitive Employment. An individual who is competitively employed performs work that is valued by an employer in an integrated setting and earns minimum wage or better. Traditionally, competitive employment options exist in most communities. Agencies such as Vocational Rehabilitation offer job placement services to eligible clients. These services are usually offered to individuals who require little training to learn job-related 
tasks and, once placed on the job, require little if any follow-up. Individuals served by Vocational Rehabilitation are placed into competitive and integrated settings. Many individuals utilizing these services are not mildly handicapped but, rather, are considered disadvantaged or displaced workers (nonhandicapped workers who have lost their jobs).

Competitive employment is also a viable alternative for persons who are severely handicapped if each of the four curriculum guides introduced earlier (communityreferenced, integrated, longitudinal, community-based) is followed. Rusch (in press) suggests that competitive employment should include intensive job-site training and advocacy, ongoing evaluation, and extended followup services. In competitive employment, ongoing services are not necessarily needed for the duration of employment (in contrast to the supported employment option) and, in fact, services are gradually withdrawn as soon as the individuals show that they can maintain employment on their own.

Although not all employment options may exist in all communities, parents should be aware of innovative employment programs occurring in other communities. The lack of various options also should not stop parents from requesting services that they think would be appropriate for their child. If parents want an employment option that does not yet exist, McDonnell et al. (undated) have suggested that parents choose an alternative that should be regarded as temporary with the understanding that a more appropriate option will be available at a later date.

\section{Students}

Students should be involved in planning their transition from school to work. As much as is possible, their interests and needs regarding various employment options should be considered.

\section{Schools}

As has been stated, schools have the responsibility to prepare students for employment. Classroom teachers should work together with the local rehabilitation agency staff to conduct surveys of communities for potential job training sites as well as permanent employment positions. It makes little sense for classroom teachers and rehabilitation personnel to conduct independent job surveys or to establish independent job training sites. These duplicative efforts - which often exist in communities could be eliminated by early coordination of services. This coordination of efforts with the local rehabilitation agency ensures that parents will be well informed of the various employment options available for their children when the children leave the school system.

\section{Adult Service Agencies}

Adult rehabilitation agency personnel (and/or employees) should be represented on the transition planning team. Reasons for involving these personnel include their need to inform teachers, parents, and students about employment options existing in the community and their need to work closely with the teachers and parents to facilitate entry into desired employment placements. Also, adult service providers should work continually to improve employment options. Expanding their access to community references is important to the continual development of their programs.

In summary, several individuals should be involved in planning the transition from school to work for individuals with severe handicaps. Parent participation is necessary because parents usually make the ultimate decision regarding the most desirable employment option for their children. The students themselves should be involved, when possible, so their vocational interests are known. The school is essential because it prepares the student for employment; and adult service agencies facilitate entry into desired employment placements and may provide further training or follow-up services. The transitional process is further enhanced by formulating a written transitional plan.

\section{The Vocational Transition Plan}

The vocational transition plan is a formal mechanism for making certain that recommendations for employment occur. Essentially, vocational transition plans should be individualized and delineate the necessary steps or procedures (e.g., type of training, materials) needed for entry into the employment option selected. The plans should specify the recommended employment option selected and designate the person(s) responsible for implementing the procedures within a specified time period. An example of a transition plan suggested by McDonnell et al. (undated) is provided in Figure 1. The vocational transition plan ensures that the parents are aware of employment options and adult services, enables the student to acquire adult services with few disruptions, and gives school personnel and adult service agency representatives a set of procedures and timelines to follow. 
High School

Participants

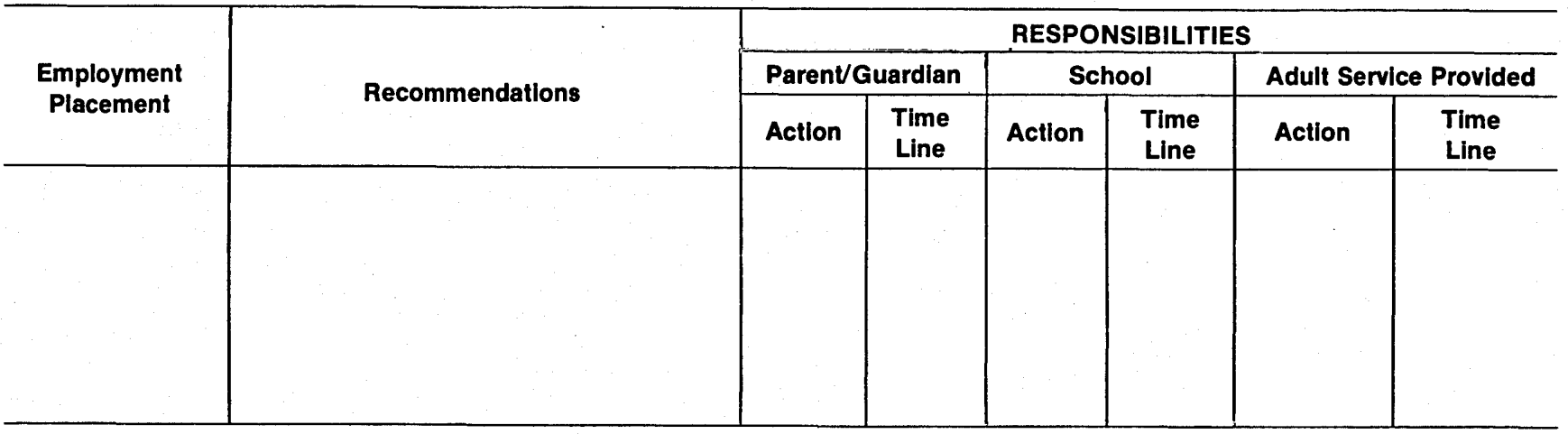

FIGURE 1

Vocational Transition Plan

\section{REFERENCES}

Alper, S. (1981). Utilizing community jobs in developing vocational curriculum for severely handicapped youth. Education \& Training of the Mentally Retarded, 16, 217-221.

Bates, P.E. (in press). Competitive employment in southern Illinois: A transitional service delivery model for enhancing competitive employment outcomes for public school students. In F.R. Rusch (Ed.), Competitive employment: Service delivery models, methods, and issues. Baltimore: Paul H. Brookes Publishing Co.

Brown, L., Pumpian, I., Baumgart, D., VanDerventer, L., Ford, A., Nisbet, J., Schneider, J., \& Gruenwald, L. (1981). Longitudinal transition plans in programs for severely handicapped students. Exceptional Children, 47, 624-630.

Hall, H.B. (1980). The intangible human factor: The most critical coordination variable. In J.O. Elder \& P.R. Magrab (Eds.), Coordinating services to handicapped children: $A$ handbook for interagency collaboration (pp. 45-62). Baltimore: Paul H. Brookes Publishing Co.

Hasazi, S., Preskill, H., Gordon, L., \& Collins, C. (1982). Factors associated with the employment status of handicapped youth. Paper presented at the American Educational Research Association, New York, NY.

Martin, J.E., Rusch, F.R., \& Heal, L.W. (1982). Teaching community survival skills to mentally retarded adults: A review and analysis. Journal of Special Education. 16(3), 243-267.

McDonnell, J., Sheehan, M., \& Wilcox, B. (undated). Effective transition from school to work and adult services: $A$ procedural handbook for parents and teachers. Eugene, OR: University of Oregon.

Mithaug, D.E., Horiuchi, C.N., \& Fanning, P.M. (1985). A report on the Colorado statewide follow-up survey of special education students. Exceptional Children, 51(5), 397-404.

Nietupski, J., Hamre-Nietupski, S., Welch, J., \& Anderson, R. (1983). Establishing and maintaining vocational training sites for moderately and severely handicapped students: Strategies for community/ vocational trainers. Education \& Training of the Mentally Retarded. 18, 169-175.

Rusch, F.R. (1979). Toward the validation of social/vocational survival skills. Mental Retardation, 17(3), 143-145.

Rusch, F.R. (1983). Competitive vocational training. In M. Snell (Ed.),
Systematic instruction of the moderately and severely handicapped (2nd ed.). Columbus, OH: Charles E. Merrill Publishing Co.

Rusch, F.R. (in press). Competitive employment: Service delivery models, methods, and issues. Baltimore: Paul H. Brookes Publishing Co.

Rusch, F., \& Mithaug, D. (1980). Vocational training for mentally retarded adults: $A$ behavior analytic approach. Champaign, IL: Research Press.

Rusch, F.R., Schutz, R.P., \& Agran, M. (1982). Validating entry-level survival skills for service.occupations: Implications for curriculum development. Journal of the Association for the Severely Handicapped, 7, 32-41.

Stainback, W., Stainback, S., Nietupski, J., \& Hamre-Nietupski, S. (in press). Establishing community-based training stations. In F.R. Rusch (Ed.), Competitive employment: Service delivery models, methods, and issues. Baltimore: Paul H. Brookes Publishing Co.

Turkel, S. (1972). Working. New York: Pantheon.

Wehman, P. (1981). Competitive employment: New horizons for the severely disabled. Baltimore: Paul H. Brookes Publishing Co.

Wehman, P. (1984). Transition for handicapped youth from school to work. In J. Chadsey-Rusch (Ed.), Conference proceedings document: Enhancing transition from school to the workplace for handicapped youth. (pp. 22-39). Champaign, IL: University of Illinois, Office of Career Development for Special Populations.

Wehman, P., Kregel, J., \& Zoller, K. (1984). A follow-up of mentally retarded graduates' vocational and independent living skills in Virginia.Manuscript in preparation, Richmond, VA.

Wilcox, B., \& Bellamy, G.T. (Eds.). (1982). Design of high school programs for severely handicapped students. Baltimore: Paul $\mathbf{H}$. Brookes Publishing Co.

Will, M. (1984, March/April). Bridges from school to working life. Programs for the Handicapped, 2.

U.S. Commission on Civil Rights. (1983). Accommodating the spectrum of disabilities. Washington, DC: Author.

This paper was supported in part by the Office of Special Education and Rehabilitative Services, United States Department of Education, pursuant to grant numbers OEG-0083-03678 and OEG-0084-30081. The opinions expressed herein do not necessarily reflect the position or policy of the Office of Special Education and Rehabilitative Services, United States Department of Education, or of the University of Illinois, and no official endorsement should be inferred. 